\title{
Adsorption of molybdenum by melanin
}

\author{
Wei Chen ${ }^{1,2}$, Kazunori Hashimoto ${ }^{1,2}$, Yasuhiro Omata ${ }^{1}$, Nobutaka Ohgami ${ }^{1,2}$, Akira Tazaki ${ }^{1,2}$, Yuqi Deng ${ }^{1,2}$,
}

Lisa Kondo-Ida ${ }^{1,2}$, Atsushi Intoh ${ }^{1,2}$ and Masashi Kato ${ }^{1,2^{*}}$

\begin{abstract}
Background: Melanin is detectable in various sense organs including the skin in animals. It has been reported that melanin adsorbs toxic elements such as mercury, cadmium, and lead. In this study, we investigated the adsorption of molybdenum, which is widely recognized as a toxic element, by melanin.

Methods: Molybdenum level of the mouse skin was measured by inductively coupled plasma mass spectrometry. The pigmentation level of murine skin was digitalized as the $L^{*}$ value by using a reflectance spectrophotometer. An in vitro adsorption assay was performed to confirm the interaction between molybdenum and melanin.

Results: Our analysis of hairless mice with different levels of skin pigmentation showed that the level of molybdenum increased with an increase in the level of skin pigmentation ( $L^{*}$ value). Moreover, our analysis by Spearman's correlation coefficient test showed a strong correlation $(r=-0.9441, p<0.0001)$ between $L^{*}$ value and molybdenum level. Our cell-free experiment using the Langmuir isotherm provided evidence for the adsorption of molybdenum by melanin. The maximum adsorption capacity of $1 \mathrm{mg}$ of synthetic melanin for molybdenum was $131 \mu \mathrm{g}$ in theory.
\end{abstract}

Conclusion: Our in vivo and in vitro results showed a new aspect of melanin as an adsorbent of molybdenum.

Keywords: Melanin, Molybdenum (Mo), Molybdate, Langmuir

\section{Introduction}

Melanin is a stable pigment that is widely found in various animals and plants [1]. Melanin is synthesized from melanocytes in various sense organs including the skin in animals [2]. Previous studies have shown the protective effects of melanin in the skin against ultraviolet light irradiation $[3,4]$. Previous studies have also shown adsorption of toxic elements such as mercury, lead [5], cadmium [6], and barium [7] by melanin. However, there is a lack of evidence for interactions of melanin with various toxic elements strictly based on chemical theory.

We previously established constitutively activated RET, a receptor-type tyrosine kinase [8-10], hairless transgenic mice (HL-RET-mice) of lines 242 and 304, which have different levels of skin pigmentation [7]. We objectively evaluated the skin pigmentations levels for HL-RET-mice of lines 242 and 304 and wild-type hairless mice as $L^{*}$ values by using a reflectance spectrophotometer $[7,11]$.

\footnotetext{
* Correspondence: katomasa@med.nagoya-u.ac.jp

${ }^{1}$ Department of Occupational and Environmental Health, Nagoya University Graduate School of Medicine, 65 Tsurumai-cho, Showa-ku, Nagoya, Aichi 466-8550, Japan

${ }^{2}$ Voluntary Body for International Health Care in Universities, Nagoya, Japan
}

Moreover, we newly showed the interaction of melanin with barium after showing that the level of barium increased with increases in the levels of pigmentation in the skin in the HL-RET-mice of lines 242 and 304 and wild-type hairless mice [7].

Molybdenum is widely recognized as a toxic element. In fact, previous studies showed that dysregulation of molybdenum was associated with neurological abnormalities [12], osteoporosis [13], and liver dysfunction [14]. At present, however, there is no chemical evidence directly showing an interaction between molybdenum and melanin.

In this study, we tried to clarify the association between melanin and molybdenum using the skin of hairless mice with different pigmentation levels. We then tried to strictly elucidate the interaction between molybdenum and melanin based on chemical adsorption theory.

\section{Materials and methods \\ Mice}

RET-transgenic hairless mice (HL-RET-mice) with constitutively different pigmentation were developed by crossing hairless mice (Hos:HRM) with RET-transgenic 
mice of lines 242 [3] and 304 [2], respectively, following the method previously described [11]. All of the mice were kept in the Animal Research Center of Nagoya University under the conditions of controlled temperature and humidity. Mice were used for digitalization of pigmentation levels in the skin and also for measurement of levels of molybdenum that had spontaneously accumulated in the skin.

\section{Digitalization for pigmentation levels of mouse skin}

Previous studies showed that a reflectance spectrophotometer (CR-400; Konica Minolta Sensing Inc., Japan) can be used to evaluate the levels of skin pigmentation in mice as well as in humans [11, 15]. Following the methods, the pigmentation level of murine skin was digitalized as the $L^{*}$ value.

\section{Measurement of molybdenum level in mouse skin}

Molybdenum level of the mouse skin was measured by inductively coupled plasma mass spectrometry (ICP-MS; $7500 \mathrm{cx}$, Agilent Technologies) following the method previously described [16]. In brief, to measure the level of molybdenum that had spontaneously accumulated in the skin, dorsal skin was obtained and digested by the wet ashing method for ICP-MS.

\section{Batch adsorption assay using synthetic melanin}

An adsorption assay using synthetic melanin (CAS \# 8049-97-6, Nacalai Tesque Inc., Japan) was performed following the method described previously [17]. The stock solution of molybdenum was prepared by dissolving ammonium molybdate (Wako Pure Chemical Industries Ltd., Japan). To determine the contact time for equilibrium adsorption, $1 \mathrm{mg}$ synthetic melanin was suspended in $400 \mu \mathrm{L}$ molybdenum solution with the concentration of $115 \mu \mathrm{g}$ molybdenum $/ \mathrm{mL}$. After incubation for $0,5,20,60,90$, and $120 \mathrm{~min}$, the suspension was centrifuged at 13,200 rpm for $10 \mathrm{~min}$ for solid-liquid separation. For adsorption kinetics and isotherm studies, 1 $\mathrm{mg}$ of synthetic melanin was incubated with $0.1,1,40$, $150,300,600,900$, and $1200 \mu \mathrm{g}$ of molybdenum $/ \mathrm{ml}$ for 60 min followed by solid-liquid separation. The concentrations of molybdenum in the supernatant and the precipitate were measured by ICP-MS after ashing the samples.

\section{Langmuir model analysis of an equilibrium adsorption isotherm}

The amount of molybdenum adsorbed by synthetic melanin was calculated by plotting $\mathrm{Ce}$ on the $x$-axis and Qe on the $y$-axis after confirming that the Langmuir adsorption isotherm model was suitable as shown previously [18]. To calculate the maximum adsorption capacity, Ce on the $x$-axis and Ce/Qe on the $y$-axis were plotted to draw Langmuir linear graph, and the predicting equation was obtained according the method previously described [19].

$$
\mathrm{QE}=V(\mathrm{Co}-\mathrm{Ce}) / \mathrm{M}
$$

Qe: molybdenum adsorbed by melanin $(\mu \mathrm{g} / \mathrm{mg})$

$V$ : volume of molybdenum solution $(0.4 \mathrm{~mL})$

Co: initial molybdenum concentration $(\mu \mathrm{g} / \mathrm{mL})$

Ce: molybdenum concentration in the supernatant $(\mu \mathrm{g} / \mathrm{mL})$

$$
\mathrm{Ce} / \mathrm{Qe}=(1 / \mathrm{a}+\mathrm{Ce}) / \mathrm{Qmax}
$$

$a$ : adsorption equilibrium constant Qmax: maximum adsorption capacity $(\mu \mathrm{g} / \mathrm{mg})$

$M$ : weight of melanin $(1 \mathrm{mg})$

\section{Statistical analysis}

Multiple comparisons were performed using one-way analysis of variance (ANOVA) with Tukey's test. The correlations were performed using Spearman coefficient. All statistical analyses were performed using SPSS 25.0 (IBM Corp., Armonk, NY, USA). $p<0.05$ was considered statistically significant.

\section{Results}

Hairless mice with different skin pigmentation levels

Skin pigmentation levels of wild-type hairless mice and HL-RET-mice of lines 242 and 304 (Fig. 1a) were digitalized by using a reflectance spectrophotometer as the $L^{*}$ value according to the method previously shown [11]. As shown in Fig. $1 \mathrm{~b}$, the $L^{*}$ values in HL-RET-mice of lines 242 and 304 were decreased by $28 \%$ and $38 \%$, respectively, compared to the $L^{*}$ value in wild-type mice, suggesting that the pigmentation levels in the skin of HL-RET-mice are increased.

\section{Correlation between levels of dorsal skin pigmentation and molybdenum}

The levels of molybdenum that had spontaneously accumulated in the dorsal skin of HL-RET-mice of lines 242 and 304 were 1.9-fold and 9.8-fold higher, respectively, than the level in wild-type mice (Fig. 2a). Moreover, there was a significant correlation $(r=-0.9441, p<0.0001)$ between the $L^{*}$ values of wild-type hairless mice and HL-RET-mice of lines 242 and 304, and the levels of molybdenum that had spontaneously accumulated in the dorsal skin by Spearman's correlation coefficient test (Fig. 2b).

\section{Adsorption of molybdenum by synthetic melanin}

Interaction between molybdenum and melanin was then examined on the basis of the chemical adsorption theory. Concentrations of melanin-bound molybdenum and unbound molybdenum are shown with time courses in Fig. 3a. The equilibrium adsorption isotherm was obtained 


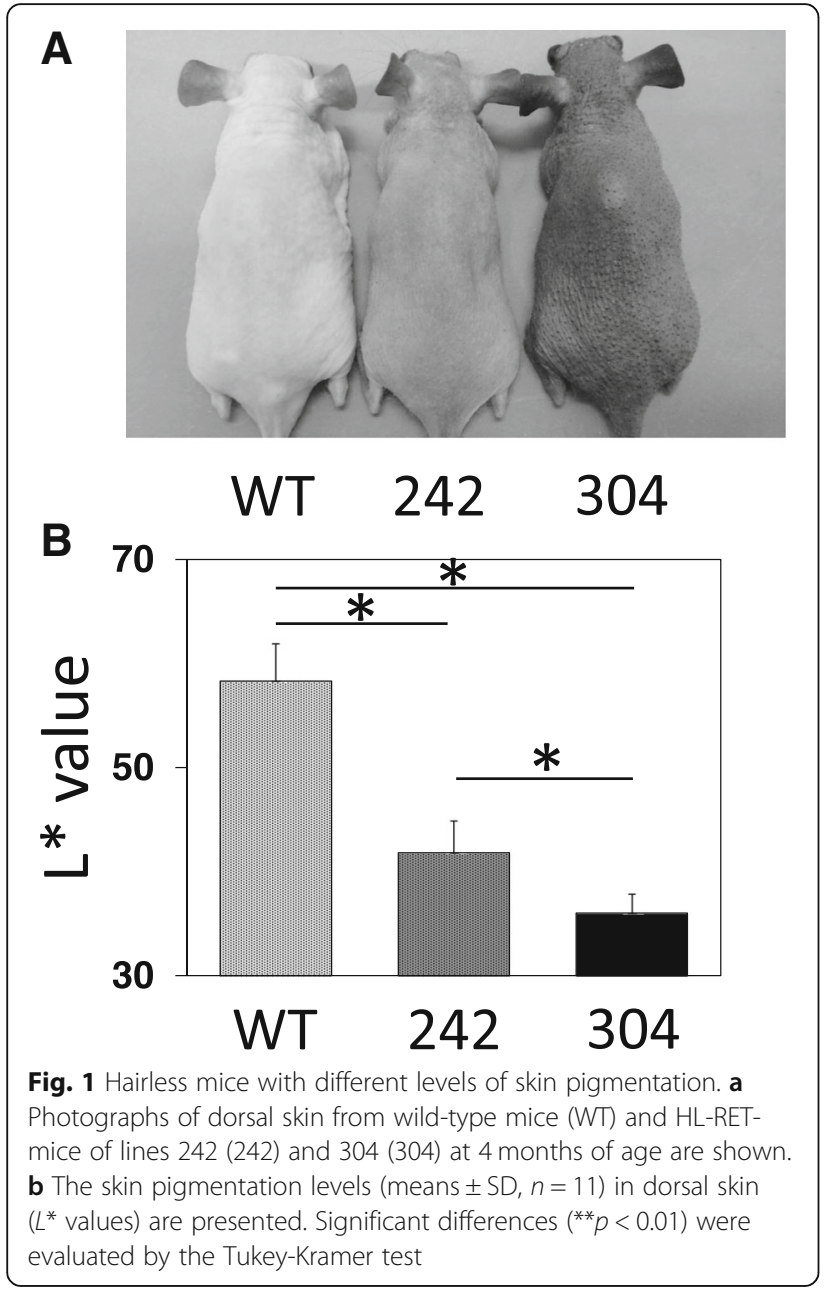

after 60-min incubation and was analyzed by the Langmuir adsorption isotherm model (Fig. 3b, c). The maximum adsorption capacity of synthetic melanin for molybdenum was $131 \mu \mathrm{g} / \mathrm{mg}$ in theory (Fig. 3c).

\section{Discussion}

We demonstrated that molybdenum levels spontaneously accumulated in the strains of mice with different levels of skin pigmentation were correlated with levels of digitalized skin pigmentation ( $L^{*}$ values). Our previous study showed a correlation $(r=-0.54)$ between barium levels and levels of digitalized skin pigmentation expressed as $L^{*}$ values after preparing genetically modified hairless mice with different pigmentation levels [7]. We then proved an interaction between synthetic melanin and barium in vitro according to the chemical adsorption theory using the Langmuir isotherm [7]. Since Spearman's correlation coefficient $(r=-0.9441)$ between molybdenum levels and $L^{*}$ values was stronger than that between barium concentrations and $L^{*}$ values, direct evidence of an interaction between synthetic melanin and molybdenum in vitro was again obtained in this study. Our results suggest that correlations between $L^{*}$ values and elements might be a useful screening system for detecting elements adsorbed by melanin as a primary screening.

Previous studies showed that the maximum adsorption capacities (Qmax) of mercury and lead to synthetic melanin synthesized from Pseudomonas stutzeri were $82.4 \mu \mathrm{g} / \mathrm{mg}$ and $147.5 \mu \mathrm{g} / \mathrm{mg}$, respectively [5]. A previous study showed that melanin purified from squid ink maximumly adsorbed $19.6 \mu \mathrm{g}$ of chromium/mg [20]. Indole-5, 6-quinone unitbased synthetic melanin maximumly adsorbed $38.5 \mu \mathrm{g}$ of
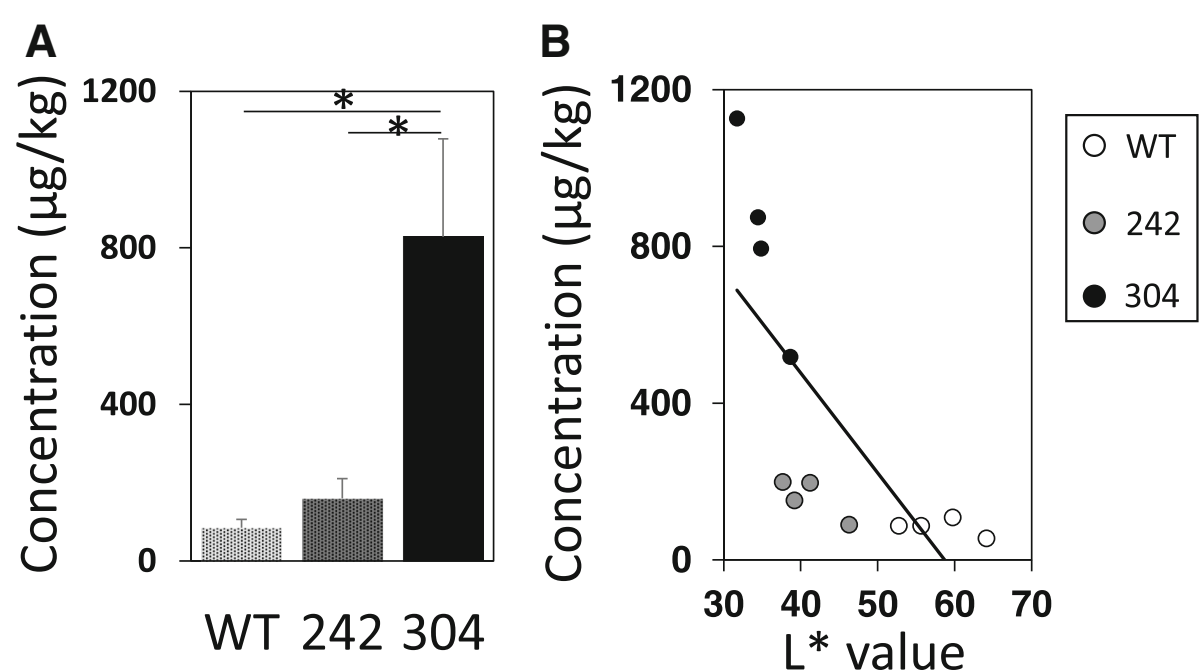

Fig. 2 Correlation between levels of skin pigmentation and molybdenum in the skin. a Molybdenum levels (means \pm SD) spontaneously accumulated in dorsal skin from wild-type hairless mice $(W T, n=4)$ and HL-RET-mice of lines $242(242, n=4)$ and $304(304, n=4)$ at 4 months of age are presented. Significant differences $\left(^{* *} p<0.01\right)$ were evaluated by the Tukey-Kramer test. $\mathbf{b}$ Correlations between levels of skin pigmentation ( $L^{*}$ values) and levels of molybdenum spontaneously accumulated in dorsal skin of wild-type hairless mice (WT, $n=4)$ and HL-RET-mice of lines 242 (242, $n=4)$ and 304 $(304, n=4)$ at 4 months of age are shown. Results analyzed by Spearman's rank correlation coefficient are presented due to no normal distribution 


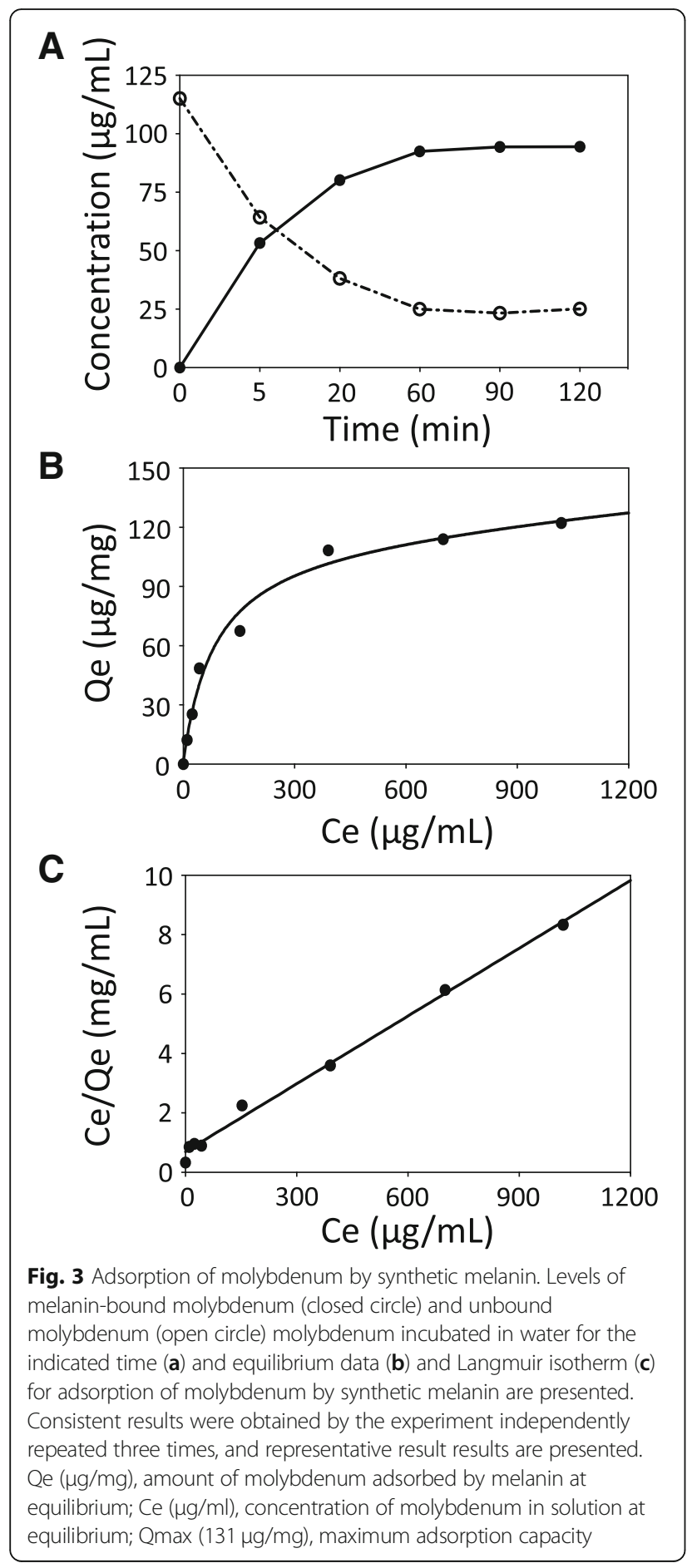

barium/mg [7]. Our results showing $131 \mu \mathrm{g}$ of molybdenum/mg as the maximum adsorption capacity of synthetic melanin may be reasonable compared with the other adsorbents previously reported as shown in Additional file 1 . Thus, synthetic melanin is a potential candidate for an adsorbent of molybdenum. It remains unclear whether adsorption of molybdenum by melanin biologically plays a beneficial role or not.
Further study is needed to clarify the biological significance of adsorption of molybdenum by melanin.

\section{Conclusion}

This study demonstrated a strong correlation between levels of skin pigmentation and molybdenum in murine skin. Our cell-free analysis then showed adsorbed molybdenum by melanin using the Langmuir isotherm. Thus, this study chemically showed a new aspect of melanin as an adsorbent of molybdenum.

\section{Additional file}

Additional file 1: Maximum adsorption capacities of melanin species for metal elements. (PPTX 39 kb)

\section{Abbreviations}

HL: Hairless; ICP-MS: Inductively coupled plasma mass spectrometry

\section{Acknowledgements}

We thank Ms. Shoko Ohnuma and Ms. Yoko Kato for ICP-MS analysis of the samples.

\section{Funding}

This study was supported in part by Grant-in-Aid for Scientific Research (A) (15H01743, 15H02588, and 19H01147), (B) (17KT0033), (C) (16

K08343 and 19K07507), and Young Scientists (19 K19408) from the Ministry of Education, Culture, Sports, Science and Technology (MEXT), Foundation for the Vitamin and Biofactor Society, Kobayashi International Scholarship Foundation, Nasu Research Foundation, EON Environmental Foundation, and Foundation from Center for Advanced Medical and Clinical Research Nagoya University Hospital.

\section{Availability of data and materials}

All data generated or analyzed during this study are available from the corresponding author on reasonable request.

\section{Authors' contributions}

WC, $\mathrm{KH}, \mathrm{YO}$, and MK conceived and designed the experiments. WC, YO, Al, and LKI performed the experiments. WC, AT, NO, and YQD analyzed and interpreted the data. WC, KH, and MK wrote the manuscript. All authors read and approved the final manuscript.

\section{Ethics approval}

Animal Care and Use Committee (approval number 30258) and Use Committee and Recombination DNA Advisory Committee (approval numbers 18-57) in Nagoya University authorized all murine experiments.

\section{Consent for publication}

Not applicable

\section{Competing interests}

The authors declare that they have no competing interests.

\section{Publisher's Note}

Springer Nature remains neutral with regard to jurisdictional claims in published maps and institutional affiliations.

Received: 1 April 2019 Accepted: 3 May 2019

Published online: 17 May 2019

\section{References}

1. Riley PA. Melanin. Int J Biochem Cell Biol. 1997;29(11):1235-9.

2. Kato M, Takeda K, Kawamoto Y, Tsuzuki T, Hossain K, Tamakoshi A, et al. Ckit-targeting immunotherapy for hereditary melanoma in a mouse model. Cancer Res. 2004;64:801-6. 
3. Kato M, Ohgami N, Kawamoto Y, Tsuzuki T, Hossain K, Yanagishita T, et al. Protective effect of hyperpigmented skin on UV-mediated cutaneous cancer development. J Invest Dermatol. 2007;127:1244-9.

4. Shirato K, Takanari J, Koda T, Sakurai T, Ogasawara J, Ohno H, et al. A standardized extract of Asparagus officinalis stem prevents reduction in heat shock protein 70 expression in ultraviolet-B-irradiated normal human dermal fibroblasts: an in vitro study. Environ Health Prev Med. 2018;23(1):40.

5. Manirethan V, Raval K, Rajan R, Thaira H, Balakrishnan RM. Kinetic and thermodynamic studies on the adsorption of heavy metals from aqueous solution by melanin nanopigment obtained from marine source: pseudomonas stutzeri. J Environ Manag. 2018;214:315-24.

6. Kim DJ, Ju KY, Lee JK. The synthetic melanin nanoparticles having an excellent binding capacity of heavy metal ions. Bull Kor Chem Soc. 2012;33:3788-92.

7. Omata Y, Yoshinaga M, Yajima I, Ohgami N, Hashimoto K, Higashimura K, et al. A disadvantageous effect of adsorption of barium by melanin on transforming activity. Chemosphere. 2018;210:384-91.

8. Kato M, Takeda K, Kawamoto Y, Tsuzuki T, Dai Y, Nakayama S, et al. RET tyrosine kinase enhances hair growth in association with promotion of melanogenesis. Oncogene. 2001;20:7536-41.

9. Omata Y, lida M, Yajima I, Takeda K, Ohgami N, Hori M, et al. Non-thermal atmospheric pressure plasmas as a novel candidate for preventive therapy of melanoma. Environ Health Prev Med. 2014;19(5):367.

10. Ohgami N, lida M, Yajima I, Tamura H, Ohgami K, Kato M. Hearing impairments caused by genetic and environmental factors. Environ Health Prev Med. 2012;18(1):10-5.

11. Kato M, lida M, Goto Y, Kondo T, Yajima I. Sunlight exposure-mediated DNA damage in young adults. Cancer Epidemiol Biomark Prev. 2011;20:1622-8.

12. Bourke CA. Molybdenum deficiency produces motor nervous effects that are consistent with amyotrophic lateral sclerosis. Front Neurol. 2016;7:28.

13. Krishnamachari KA, Krishnaswamy K. An epidemiological study of the syndrome of genu valgum among residents of endemic areas for fluorosis in Andhra Pradesh. Indian J Med Res. 1974;62:1415-23.

14. Kovalsky $\mathbf{W}$. The change in purine metabolism of humans and animals under the conditions of molybdenum biogeochemical provinces. Zh Obshch Biol. 1961;22:179-91.

15. Yajima I, Ahsan N, Akhand AA, Al Hossain MA, Yoshinaga M, Ohgami N, et al. Arsenic levels in cutaneous appendicular organs are correlated with digitally evaluated hyperpigmented skin of the forehead but not the sole in Bangladesh residents. J Expo Sci Environ Epidemiol. 2016;28:64.

16. Kato M, Kumasaka MY, Ohnuma S, Furuta A, Kato Y, Shekhar HU, et al. Comparison of barium and arsenic concentrations in well drinking water and in human body samples and a novel remediation system for these elements in well drinking water. PLoS One. 2013;8(6):e66681 Deli MA, editor.

17. Kumasaka MY, Yamanoshita O, Shimizu S, Ohnuma S, Furuta A, Yajima I, et al. Enhanced carcinogenicity by coexposure to arsenic and iron and a novel remediation system for the elements in well drinking water. Arch Toxicol. 2013;87:439-47.

18. Kato M, Azimi MD, Fayaz SH, Shah MD, Hoque MZ, Hamajima N, et al. Uranium in well drinking water of Kabul, Afghanistan and its effective, low-cost depuration using mg-Fe based hydrotalcite-like compounds. Chemosphere. 2016;165:27-32.

19. Yoshinaga M, Ninomiya H, Al Hossain MA, Sudo M, Akhand AA, Ahsan N, Alim MA, Khalequzzaman M, lida M, Yajima I, Ohgami N. A comprehensive study including monitoring, assessment of health effects and development of a remediation method for chromium pollution. Chemosphere. 2018;201:667-75.

20. Cuong AM, Le Na NT, Thang PN, Diep TN, Thuy LB, Thanh NL, et al. Melanin-embedded materials effectively remove hexavalent chromium (CrVI) from aqueous solution. Environ Health Prev Med. 2018;23(1):9.

\section{Ready to submit your research? Choose BMC and benefit from:}

- fast, convenient online submission

- thorough peer review by experienced researchers in your field

- rapid publication on acceptance

- support for research data, including large and complex data types

- gold Open Access which fosters wider collaboration and increased citations

- maximum visibility for your research: over $100 \mathrm{M}$ website views per year

At BMC, research is always in progress.

Learn more biomedcentral.com/submissions 